\title{
Full Fabrication and Packaging of an Implantable Multi-Panel Device for Monitoring of Metabolites in Small Animals
}

\author{
Camilla Baj-Rossi, Enver G. Kilinc, Sara S. Ghoreishizadeh, Daniele Casarino, Tanja Rezzonico Jost, \\ Catherine Dehollain, Fabio Grassi, Laura Pastorino, Giovanni De Micheli, and Sandro Carrara
}

\begin{abstract}
In this work, we show the realization of a fully-implantable device for monitoring free-moving small animals. The device integrates a microfabricated sensing platform, a coil for power and data transmission and two custom designed integrated circuits. The device is intended to be implanted in mice, free to move in a cage, to monitor the concentration of metabolites. We show the system level design of each block of the device, and we present the fabrication of the passive sensing platform and its employment for the electrochemical detection of endogenous and exogenous metabolites. Moreover, we describe the assembly of the device to test the biocompatibility of the materials used for the microfabrication. To ensure biocompatibility, an epoxy enhanced polyurethane membrane was used to cover the device. We proved through an in-vitro characterization that the membrane was capable to retain enzyme activity up to 35 days. After 30 days of implant in mice, in-vivo experiments proved that the membrane promotes the integration of the sensor with the surrounding tissue, as demonstrated by the low inflammation level at the implant site.
\end{abstract}

Index Terms-Biocompatible packaging, biosensors, chronoamperometry, cyclic voltammetry, implantable electronics, powering system.

\section{INTRODUCTION}

$\mathbf{E}$ LECTROCHEMICAL sensors for continuous monitoring of glucose and lactate are already in the market [1], moreover, first prototypes of fully implantable glucose sensors have been validated up to 8 months in mice [2] and up to one year in pigs [3]. The continuous monitoring of endogenous molecules

Manuscript received March 06, 2014; revised July 04, 2014; accepted August 30, 2014. Date of publication October 13, 2014; date of current version November 06, 2014. This research was supported by the SNF Sinergia Project, code CRSII2 147694/1 and title "Innovative Enabling Micro-Nano-Bio-technologies for Implantable systems in molecular medicine and personalised therapy project prolongation," and in part by the NanoSys project, within the frame of the UE program ERC-2009-AdG-246810. This paper was recommended by Associate Editor S. Renaud.

C. Baj-Rossi, S. S. Ghoreishizadeh, G. De Micheli, and S. Carrara are with the Laboratory of Integrated Systems, Swiss Federal Institute of Technology (EPFL), 1015 Lausanne, Switzerland (e-mail: camilla.baj-rossi@epfl.ch).

E. G. Kilinc and C. Dehollain are with the RFIC Group, Swiss Federal Institute of Technology (EPFL), 1015 Lausanne, Switzerland.

D. Casarino and L. Pastorino are with the Department of Informatics, Bioengineering, Robotics and Systems Engineering, University of Genova, 16145 Genova, Italy.

T. R. Jost and F. Grassi are with the Institute for Research in BiomedicineIRB, 6500 Bellinzona, Switzerland.

Color versions of one or more of the figures in this paper are available online at http://ieeexplore.ieee.org.

Digital Object Identifier 10.1109/TBCAS.2014.2359094 (e.g., glucose, lactate, ATP) in mice, enables understanding of animal model metabolism in translational medicine [4]. The development of an implantable device for monitoring also exogenous substances, such as drugs, would represent a big step towards personalized medicine, because it would enable the individual adjustment of the drug dosage and, therefore, it would increase the accuracy and efficacy of the treatment and reduce dangerous adverse drug reactions, especially for patients with critical or chronic conditions [5].

Electrochemical sensors are the ideal devices for these applications by providing rapid, accurate and quantitative detection of analytes with an inexpensive and simple to use set-up [5]. An implantable device capable of monitoring multiple substances should contain an array of sensors with enough sensitivity to monitor drugs and metabolites within the therapeutic range. The sensor sensitivity is improved by using nanostructured materials. In our previous works we proved that carbon nanotubes (CNTs) clearly provide great advantages when used in electrochemical biosensing [6], in terms of sensitivity and detection limit. However, since CNTs may be potentially toxic, the biocompatibility of devices incorporating nanomaterials needs to be investigated. The biocompatibility and the sensor stability in time are other fundamental issues for implantable devices: the sensor should be well tolerated by the host and cause a limited foreign body reaction, and at the same time the contact with biological fluids should not significantly affect sensor performances [7]. Moreover, an implantable device should contain the required electronics in order to supply enough power for the biosensor and for the data transmission. It is therefore necessary to power the system externally because available batteries in the market are bulky, heavy, they would need replacement, and because batteries would increase the dimensions of the final device.

The present work focuses on the design, fabrication, characterization and packaging of a fully-implantable device for the continuous monitoring of drug and metabolite concentration in mice. Small animal models are increasingly being used in the first phase of clinical trials for drug development. The living conditions of these animals are of primary importance because the stress level can affect the measurement results. This means that the animal must be in a comfortable environment and capable to freely move. Therefore, the final aim of our work is to monitor the animal in a living space, such as a cage, and the power must be continuously transferred to the implantable 
system according to the position of the animal [8]. The fullyimplantable device consists of: 1) a passive sensing platform, 2) integrated circuits (ICs) to perform electrochemical measurements and 3) a coil for power and data transmission. The device is intended to be implanted subcutaneously in the back of mice.

In the recent literature, a number of integrated systems for biomedical implants have been reported. However the comparison with our system is not so straightforward, because some works focus on different applications [9], [10], some works do not target any specific applications [11], [12], other works present measurements of a single metabolite [13], or have batteries [14].

In the first part of the result section (Section II) we present the design and fabrication of each single block. The materials and methods are reported in Section III. In the Section IV, we show the characterization of the passive sensing platform, obtained with the commercial potentiostat, and also some measurements performed with the autonomous system that consists on the integration of the passive platform, ICs and the powering system described in Section II. In the Section V, we show the assembly of these components and the use of an innovative biocompatible packaging based on an epoxy enhanced polyurethane membrane. After an in-vitro characterization, we finally demonstrated the biocompatibility of the chip and the membrane with in-vivo biocompatibility tests, by implanting the devices in mice for 30 days.

\section{IMPLANTABLE BIOSENSOR: DESIGN AND FABRICATION}

In this section we present an overview of the implantable biosensor system design. We first show the design of the control and readout IC, the transmitter, of the power management IC and of the inductive link, with details about the design of the remote powering system and fabrication of the coils. In the first three subsections, details on the design and the performance parameters are presented for each block. Finally, in the last subsection we describe the design and fabrication steps for the passive sensing platform.

\section{A. Application Scenario}

Since the stress level changes the measurement result, the animal needs to be in a natural environment and to move freely. Therefore, the animal must be monitored in a living space and the power must be transferred to the implantable system continuously. We decided to monitor the animal free to move inside a cage used in the laboratory. And an intelligent remote powering (IRPower) system is proposed for continuous long-term monitoring and to deliver the power efficiently though an optimized inductively coupled power link. Fig. 1 shows the scenario of the implantable sensor system for the freely moving animal. The IRPower system consists of detection and movement blocks [15], [16]. The detection block is used to find and track the animal in the living space. The magnetic field sensors are used to find and track the permanent magnet which is implanted in the animal. The movement block has $\mathrm{X}$ and $\mathrm{Y}$ rails to move the powering coil to concentric position with the implanted coil where the efficient power transfer is assured. The rails move at maximum speed of $30 \mathrm{~cm} / \mathrm{s}$ which is sufficient to track a mouse in a living space.

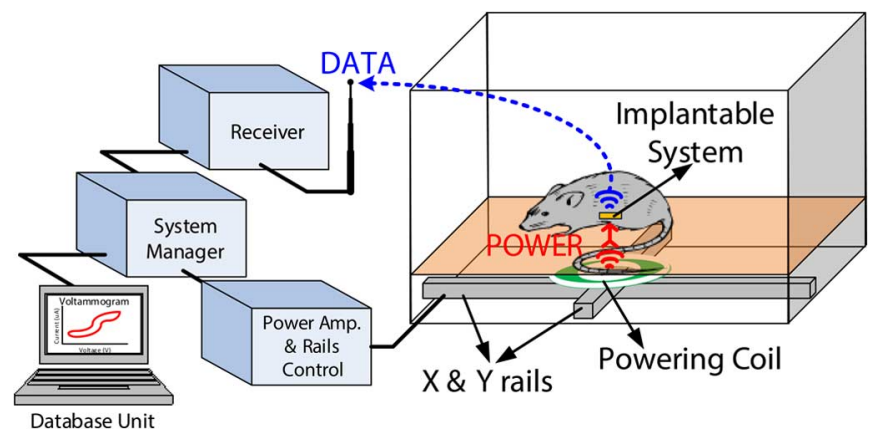

Fig. 1. Scheme of the implantable sensor system for a freely moving animal.

\section{B. Integrated Circuits and Communication Protocol Design}

Fig. 2 shows the block diagram of the implantable biosensor system. The power is transferred over an optimized remote powering link which is driven by an efficient class-E power amplifier. The overall power efficiency of the inductive link is $21 \%$ including the drain efficiency of the power amplifier.The induced voltage at the implantable system is proportional to the remote powering frequency. On the other hand, the penetration depth of the power in the body decreases with frequency. Therefore, an optimal frequency is necessary [17]. An ISM band which is 13.56 MHz is chosen for the wireless power transmission. A second channel is preferred for a reliable data transmission due to the moving animal. When the animal moves, the coupling between the coils changes and the received power at the implant changes. Using the same inductive link for power and communication does not allow a reliable data transmission. Accordingly, the data is transmitted over a second channel at $869 \mathrm{MHz}$ by an on-off keying (OOK) transmitter.

The induced voltage is converted to a DC voltage with more than $80 \%$ of power efficiency by a passive full-wave rectifier. A low-drop out (LDO) voltage regulator follows the rectifier to create $1.8 \mathrm{~V}$ supply voltage for the bio-sensor system. The PSRR value of the voltage regulator is more than $60 \mathrm{~dB}$ at 27.12 MHz. The reference voltage for the voltage regulator is generated on chip by a fully CMOS voltage generation circuit.

The regulated voltage is given to the waveform generator and the readout and control circuits as the supply voltage. The waveform generator is a mixed-mode circuit to generate different voltage waveforms to control cyclic voltammetry $(\mathrm{CV})$ and programmable constant voltage levels to enable chronoamperometry (CA), by using a single mixed-signal circuit. The control and readout circuit applies this waveform to the biosensor and measures the resulted sensor current as shown in Fig. 2. This block controls and reads out the sensor array as well as $\mathrm{pH}$ and temperature sensors for calibration purpose. It consists of programmable gain amplifiers and a second-order sigma delta analog to digital converter as well as a temperature readout circuit. An on-chip multiplexer decides which sensing site should be connected to the readout circuit. The digital output of the converter goes through an $8 \mathrm{~b} / 10 \mathrm{~b}$ encoding for DC-balancing and to prevent long sequence of similar logic in communication. It consumes $500 \mu \mathrm{A}$ from a $1.8 \mathrm{~V}$ supply voltage. More information about the design of the readout and control IC can be found in [18]. We have also developed another type of CA 


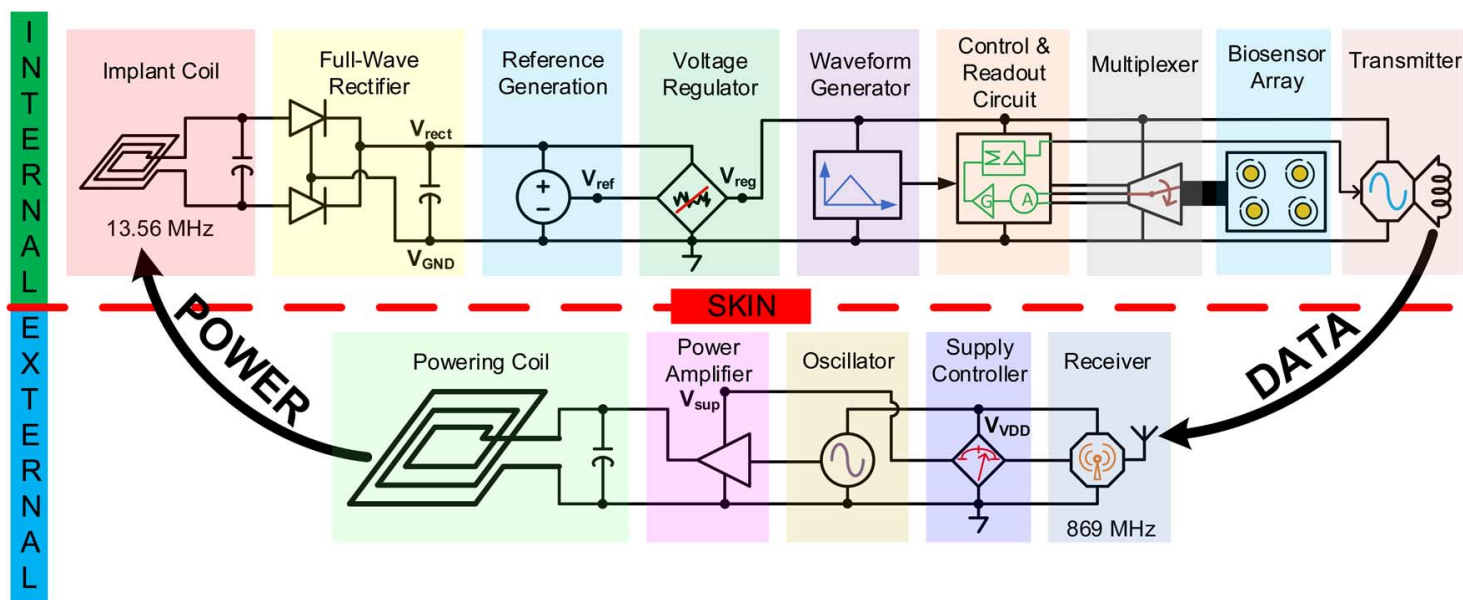

Fig. 2. Block diagram of the implantable biosensor system.

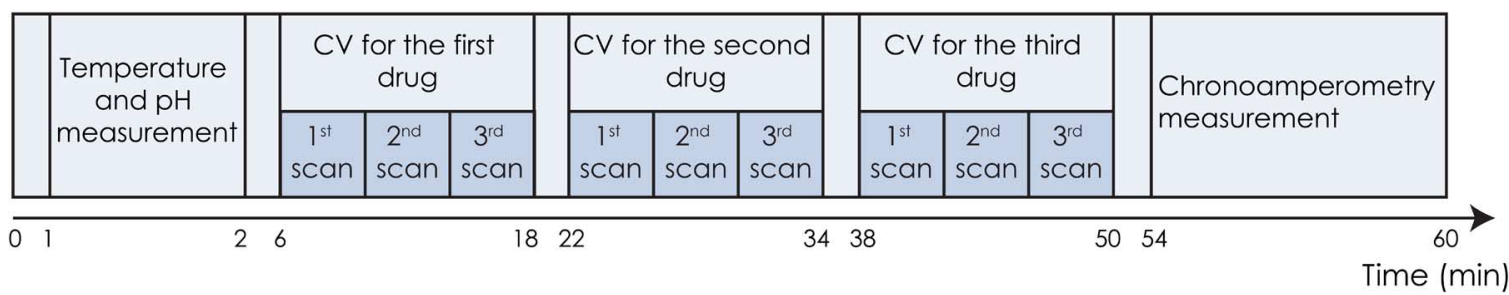

Fig. 3. Timing schedule for the measurements.

and $\mathrm{CV}$ readout circuit based on current to frequency conversion [19]. A sample timing schedule for the measurements is shown in Fig. 3. The control and readout circuit has been designed to run the measurements according to this schedule. It measures three different drugs out of three different sensing sites by $\mathrm{CV}$ and a single metabolite by $\mathrm{CA}$ on the fourth sensing site. Prior to these measurements, $\mathrm{pH}$ and the temperature of the solution are measured. It is well-known that changes in $\mathrm{pH}$ or temperature could affect the current response in both $\mathrm{CV}$ and $\mathrm{CA}$ measurements [20]. Thus, the control over $\mathrm{pH}$ and temperature enables to correct eventual changes in the current response, during the data post-processing. More information about the design of the readout and control IC can be found in [18], [21].

Transmitter is one of the most power hungry blocks in a system. Therefore, a low-power transmitter is essential to reduce the power consumption. OOK transmitter is a well-known method for data communication in implantable biomedical systems [22]. Although the transmitter saves energy during transmitting bit "0", the transmitter still consumes high power due to the power amplifier. Accordingly, the proposed OOK transmitter excludes the power amplifier for short range communication and consists of a free running LC oscillator which reduces the overall power consumption of the biosensor system. In addition, the transmitter's inductor is designed as a loop antenna for short-range communication. The data is received by a custom design receiver at $869 \mathrm{MHz}, 40 \mathrm{~cm}$ away. The transmitter consumes $180 \mu \mathrm{A}$ at $1.8 \mathrm{~V}$ supply voltage, and it allows a reliable data communication with a data rate of $1.5 \mathrm{Mbps}$.

An optimized inductively coupled power link is designed for an efficient power delivery. The load of the biosensor system can vary. Therefore, the required power at the implantable

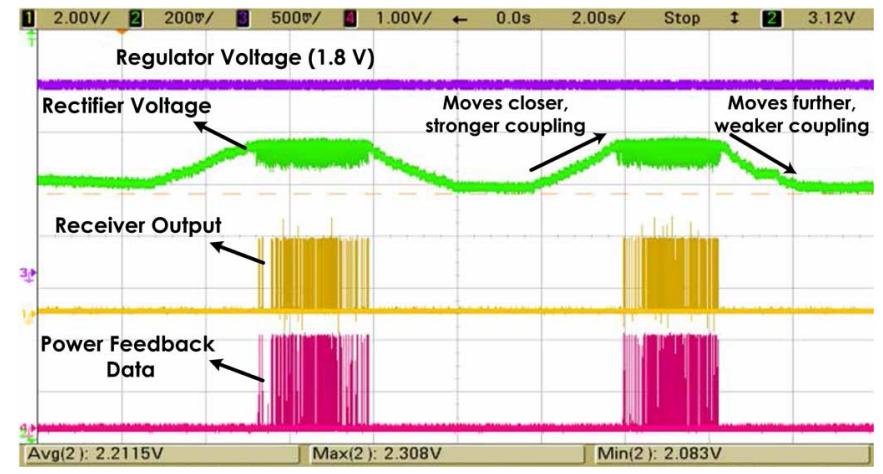

Fig. 4. Remote powering signals and power feedback data for power adaptation.

system can change. Moreover, the coupling between the powering and implant coils may change due to the movement of the animal and hence the received power at the implantable system can change. Accordingly, a power adaptation technique is used to transmit sufficient power to the implantable system: the power level at the implantable system is transmitted to the external unit. The supply voltage of the power amplifier is adjusted and hence the transmitted power changes according to the power feedback data. Fig. 4 shows the remote powering signals and power feedback data for power adaptation. When the implant coil moves closer to the center of the powering coil, the received power by the implantable system increases. Therefore, the rectifier voltage increases. The transmitted power level is adjusted by tracking the rectifier voltage and transmitting power feedback data to the external base station. The implantable circuits have been designed and realized in 
TABLE I

INDUCTIVE-LINK PERFORMANCE COMPARISON

\begin{tabular}{ccccccc}
\hline Reference & Year & Application & $\begin{array}{c}\text { Frequency } \\
(\mathrm{MHz})\end{array}$ & $\begin{array}{c}\text { Efficiency } \\
(\%)\end{array}$ & $\begin{array}{c}\text { Distance } \\
(\mathrm{cm})\end{array}$ & $\begin{array}{c}\text { Power } \\
(\mathrm{mW})\end{array}$ \\
\hline Cong et al. [24] & 2010 & Blood pressure & 4.0 & N/A & 1 & 0.3 \\
Hsieh et al. [25] & 2013 & Long-term monitoring & 0.125 & N/A & N/A & 12 \\
Mirbozorgi et al. [26] & 2014 & Animal research & 13.56 & 76 & 4 & 115 \\
Present work & 2014 & Multi biosensor & 13.56 & 21 & 3 & 2 \\
\hline
\end{tabular}

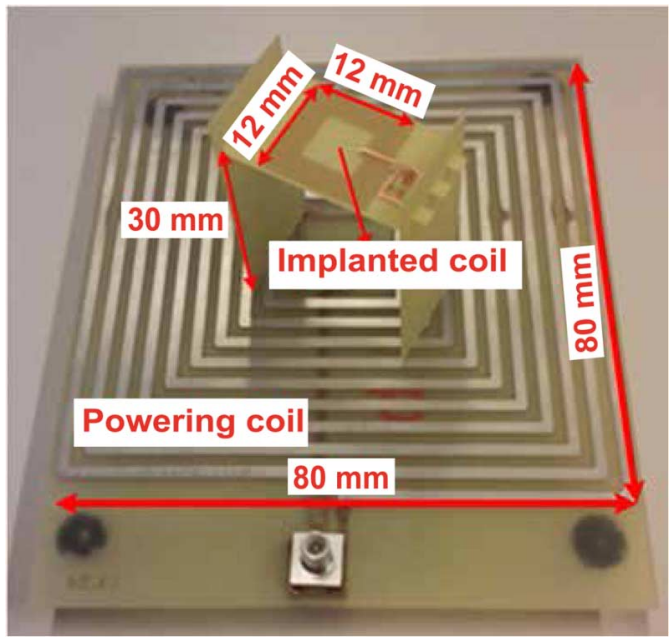

Fig. 5. Optimized power link.

$180 \mathrm{~nm}$ technology. More information about the power management and transmitter can be found in [8], [23]. The overall power consumption of the system is less than $1.6 \mathrm{~mW}$. In the Table I, the performance of the presented inductive-link system are compared with other similar system existing in literature.

\section{Coil Design and Fabrication}

The coupling of the coils is a critical parameter to increase the power transfer efficiency especially when the distance between the coils is large. To obtain the optimal remote powering link, we proposed a combination of two approaches: analytical equations and a 3-D high frequency simulation software [17]. In the optimization method, each geometric parameter of the coils was swept to obtain the optimal coil pair. Accordingly, the lumped model parameters of the remote powering link were extracted by using analytical equations and a field solver software. The power transfer efficiency of the remote powering link was calculated and the geometric parameters of the coils were characterized in 3-D electromagnetic field simulation software (HFSS). Finally, the coils were produced on printed circuit board (PCB) for reliability and reproducibility and characterized for operation frequency. The materials used were copper on a FR4 substrate. Fig. 5 shows the optimized inductively coupled power link, where the implanted coil is showed on the top of the powering coil for a better comparison. The sizes of the powering and implanted coils are $80 \times 80 \mathrm{~mm}$ and $12 \times 12 \mathrm{~mm}$, respectively, and the power transfer efficiency is limited over $30 \mathrm{~mm}$ distance [16].

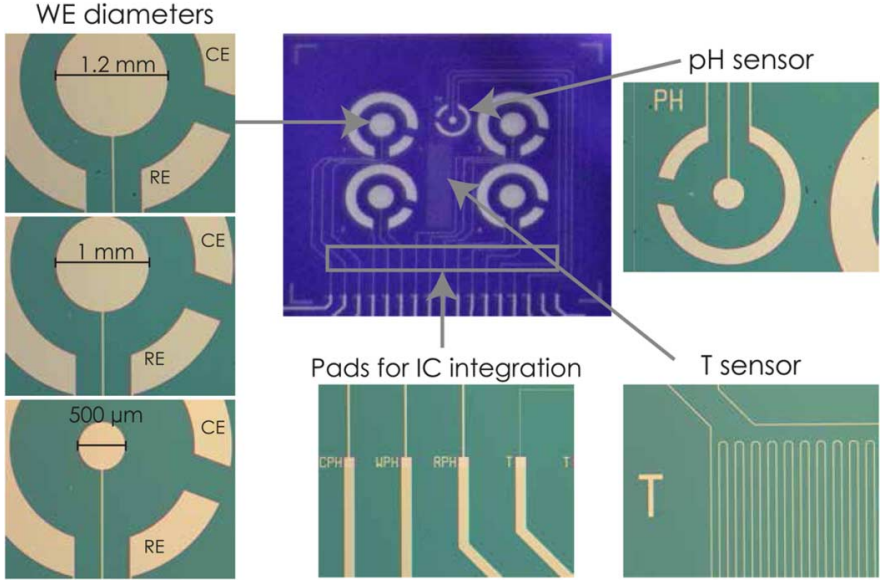

Fig. 6. Photographs of the microfabricated platform (center), with the three geometries for the working electrode (WE), the pads for integration with ICs, the $\mathrm{pH}$ sensor and the temperature sensor.

\section{Design and Fabrication of the Passive Chip}

The microfabrication of the passive chip was realized with a two-masks process flow. Details on the process flow can be found in [27]. The design of the passive chip was done under the constraints given by the compatibility with the other components. The platform measures $12 \times 11 \mathrm{~mm}$ in order to fit the size of the coil $(12 \times 12 \mathrm{~mm})$ and the wire bonding. Fig. 6 shows the photograph of the passive chip with the main structures. The platform hosts an array of four independent cells in the three-electrode configuration: a working electrode (WE), a counter electrode (CE) and a reference electrode (RE), all made in Pt. Working electrodes were realized in three different geometries (diameter of $500 \mu \mathrm{m}, 1 \mathrm{~mm}$ and $1.2 \mathrm{~mm}$ ). The main advantage behind the design of an array of independent sensors is the possibility to perform multiplexed measurements of drugs or metabolites.

A pH sensor and a temperature sensor were fabricated in Pt. The $\mathrm{pH}$ sensor has been designed in two versions: one has a WE with a $300 \mu \mathrm{m}$ diameter (showed in Fig. 6), while the second version has a squared WE of $250 \times 250 \mu \mathrm{m}^{2}$. Both versions are based on an anodic iridium oxide film in order to compare them with our previous results [27]. The resistive thermal device (RTD) consists of a Pt wire (4 $\mathrm{nm}$ width and $93 \mathrm{~mm}$ length) with an average resistivity of $34 \mathrm{k} \Omega$ at $20^{\circ} \mathrm{C}$, compatible with the power constraints. The design of a sensing platform for electrochemical measurement, combined with the presence of a $\mathrm{pH}$ and a temperature sensor, is a strategy to optimize the sensing performance in different physiological conditions, since changes in $\mathrm{pH}$ and temperature can affect the sensor specificity [20]. In the 
next paragraphs we will show that our microfabricated platform can be exploited for the monitoring of multiple substances.

\section{Materials AND MethodS}

\section{A. Passive Chip Microfabrication}

Microfabrication was realized at the EPFL Centre of Micronano Technology (CMI). Silicon wafers with $500 \mathrm{~nm}$ of native oxide were chosen as substrate. Chip metalization was realized by evaporation of $10 \mathrm{~nm}$ of Ti, followed by $100 \mathrm{~nm}$ of Pt. Metal passivation was made via atomic layer deposition of $\mathrm{Al}_{2} \mathrm{O}_{3}$, followed by dry etching with Argon Ion Milling. Details on the microfabrication can be found in [27].

\section{B. Sensors Functionalization and Membrane Deposition}

1) Chemicals: Multi-walled carbon nanotubes (MWCNTs, $\sim 10 \mathrm{~nm}$ diameter and $\sim 1-2 \mu \mathrm{m}$ length) with $5 \%-\mathrm{COOH}$ groups content, were purchased as a powder ( $90 \%$ purity) from DropSens (Spain). For the drop-cast deposition, a $1 \mathrm{mg} / \mathrm{ml}$ solution of MWCNTs, prepared in chloroform, was sonicated for $3 \mathrm{~h}$ to obtain a homogeneous suspension [28]. For electrodeposition, MWCNTs in powder were dispersed in chitosan $(0.7 \% \mathrm{w} / \mathrm{v}, \mathrm{pH} 5)$ and then sonicated for $3 \mathrm{~h}$ to obtain a $8 \mathrm{mg} / \mathrm{ml}$ solution. All experiments were carried out in a $100 \mathrm{mM}$ phosphate buffered saline solution (PBS, $\mathrm{pH}$ 7.4) as supporting electrolyte.

Glucose oxidase (GOx) from Aspergillus Niger was purchased from Roche in lyophilizate powder and dissolved in a $100 \mathrm{mM}$ PBS (pH 5.86). $D-(+)$-glucose was purchased from Sigma-Aldrich (Switzerland) in powder and dissolved in in Milli-Q water. Etoposide (ETO) and mitoxantrone (MTX) were purchased as a powder from Sigma-Aldrich. Due to their low solubility in water, ETO and MTX solutions at different concentration were prepared by dissolving them in Dimethyl sulfoxide (from Sigma Aldrich) before storage at room temperature.

For the $\mathrm{pH}$ sensor, a solution of Iridium(IV) chloride hydrate (99.9\% metals basis, from Sigma Aldrich), $\mathrm{H}_{2} \mathrm{O}_{2}$ (30\%), Oxalic acid dihydrate (98\%, from Sigma Aldrich), and Potassium carbonate anhydrous ( $99 \%$, from Alfa Aesar) was prepared for the deposition of the Iridium Oxide film (IrOx), as reported in [29].

2) Electrode Preparation and Functionalization: We performed electrochemical measurements with both carbon paste screen-printed electrodes (SPEs, model DRP-110, DropSens) and the microfabricated passive platform. The working electrode of SPEs was nanostructured with $30 \mu \mathrm{g}$ MWCNTs as reported in [28]. For the microfabricated platform, some working electrodes were functionalized by electrodeposition of a chitosan/MWCNT dispersion $8 \mathrm{mg} / \mathrm{ml}$, by applying a fixed potential of $1.5 \mathrm{~V}$ for $2400 \mathrm{~s}$ [27]. A $15 \mathrm{mg} / \mathrm{ml}$ solution of GOx was drop cast on some working electrodes and stored overnight at $4{ }^{\circ} \mathrm{C}$. All the samples were freshly prepared and used the same day. When not in use, electrodes were stored at $4^{\circ} \mathrm{C}$. For the measurements in $\mathrm{CV}$, the electrodes were used without modifications.

For the $\mathrm{pH}$ sensor we used a squared electrode $(250 \times$ $250 \mu \mathrm{m}^{2}$ ) in a passive platform that we previously realized
[27]. A layer of IrOx was created on the electrode surface by galvanostatic deposition, by applying a constant current of $0.9375 \mu \mathrm{A}$ for $500 \mathrm{~s}$. After a stabilization in PBS pH 7.4 for 2 days to reduce potential drift, the electrodes were tested for $\mathrm{pH}$ sensing.

\section{Electrochemical Measurements}

To verify the passive sensing plaform, electrochemical measurements were performed using an Autolab electrochemical workstation (Metrohm, Switzerland). Electrodes were tested for glucose sensitivity with $\mathrm{CA}$ at $+650 \mathrm{mV}$. The sensors were first dipped in a $100 \mathrm{mM}$ PBS solution (pH 7.4), under stirring conditions, then conditioned for $1 \mathrm{~h}$ at $+650 \mathrm{mV}$ and then tested against repeated injections of glucose. CV was used to identify the oxidation/reduction peaks of ETO and MTX. CV was performed at room temperature under aerobic conditions by applying a triangular waveform voltage in the range between $-600 \mathrm{mV}$ and $+800 \mathrm{mV}$ versus $\mathrm{Pt}$, with scan rate of $20 \mathrm{mV} / \mathrm{s}$. After an initial conditioning in PBS, drops of $200 \mu \mathrm{l}$ of ETO or MTX solutions were added at the right concentration. CV measurements were also performed with our autonomous microsystem that consists on the integration of: (i) the inductive coil; (ii) the power management IC; (iii) the interface IC to control and readout the biosensor; and (iv) the biosensor.

$\mathrm{pH}$ was computed averaging the open circuit potential (OCP) in a time window of around $120^{\prime \prime}$ by continuously changing the $\mathrm{pH}$ of the buffer solution by means of an external $\mathrm{pH}$ meter (from VWR). An external reference electrode (double junction in $\mathrm{Ag} \mid \mathrm{AgCl}$ ) was used in order to have stable and reproducible measurements. For the temperature sensor, a True RMS Multimeter 37XR (Wavetek Meterman) was connected to our platform to measure the changes in resistivity.

Sensitivity and limit of detection (LOD) are the key parameter used to evaluate the sensing performances. Sensitivity per unit area was computed from the slope of the straight line obtained by plotting the current steps versus glucose or drug concentration. The LOD was computed as three times the signal-to-noise ratio according to the expression $L O D=k(\delta i / S)$, where $\delta i$ is the standard deviation of the blank measurements, $S$ is the sensitivity, and $k$ is a parameter accounting for the confidence level ( $k=1,2$, or 3 corresponds to $68.2 \%, 95.4 \%$, or $99.6 \%$ of statistical confidence), according to [30].

\section{Integrated Device Assembly}

The epoxy adhesive (EP42HT-2Med system) was used to assembly the electronic component in the integrated device. The interconnections between the pads of the passive chip and electronic components were realized with $\mathrm{Al}$ wire bonding and were protected with a glob top protection of $0.3 \mathrm{~mm}$. All the edges of the device were rounded with a milling machine. Two subsequent $5 \mu \mathrm{m}$ layers of Parylene $\mathrm{C}$ were deposited by chemical vapor deposition using a Comelec C-30-S Parylene Deposition System. Parylene $\mathrm{C}$ was used to cover the whole device but not the electrode array that needs to be in contact with fluids. Fig. 7 shows the components of the implantable device. Finally, the electrodes were functionalized with MWCNTs and the device 


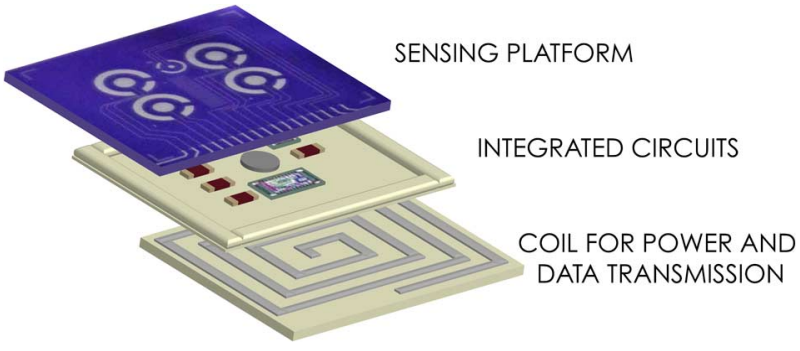

Fig. 7. Scheme of the integrated device assembly.

was covered with three layers of a biocompatible membrane as described in the next section.

\section{E. Biocompatible Membrane}

For the biocompatible membrane, a homogeneous solution was obtained by mixing $125 \mathrm{mg}$ of an epoxy adhesive (EP42HT-2Med system), purchased by Master Bond (Hackensack, USA) as a certified biocompatible two-components adhesive, $112.5 \mathrm{mg}$ of Polyurethane (PU, Sigma Aldrich), $12.5 \mathrm{mg}$ of the surfactant agent Polyethylene glycol ether (Brij 30, Sigma Aldrich), for $10 \mathrm{ml}$ of Tetrahydrofuran (THF, Sigma Aldrich) used as solvent.

The deposition method of the biocompatible membrane is known as dip coating and it consists of a quick immersion of the sensor in the membrane solution. Subsequent depositions were applied at $2 \mathrm{~h}$ intervals and then the sensors were stored overnight at room temperature. A fast curing at high temperature $\left(2 \mathrm{~h}\right.$ at $\left.80^{\circ} \mathrm{C}\right)$ is needed to ensure the biocompatibility of the resin. After this process the sensors were again kept overnight at room temperature, and then stored in PBS one day for membrane swelling.

\section{F. In-Vivo Biocompatibility}

The animals were bred and treated in accordance with the Swiss Federal Veterinary Office guidelines and were kept in specific pathogen-free animal facility. Experiments were approved by "Dipartimento della Sanitá e Socialitá" with authorization number TI-19/2010. Microchips were cleaned and disinfected with ethanol $70 \%$ and placed in sterile PBS (Gibco) for $24 \mathrm{~h}$ to stabilize the membrane. An Air Pouch (AP) was created by subcutaneous injection of sterile air in the back of male C57BL/6 mice at day $1(5 \mathrm{~mL})$ and day $3(3 \mathrm{~mL})$ : this procedure creates a cavity of $1.5 \mathrm{~cm}$ diameter and $0.5 \mathrm{~cm}$ height. At day 6 , mice were anesthetized with isoflurane $4 \%$, shaved and locally sterilized with Betadine solution; the sterile microchips were implanted and the cavity sutured with Vicryl 6.0 (Provet AG). As a control of local inflammation, bacterial lipopolysaccharide (LPS) (50 $\mu \mathrm{g} /$ mouse) (LabForce AG) was injected daily into the cavity for the last 2 weeks of the 30 days of the experiment. As negative control APs were generated in the absence of any surgical procedure. As further control commercial chips (DATA MARS) were injected through sterile needle. After 30 days, the microchips were removed. The cavity was rinsed with $0.5 \mathrm{~mL}$ of PBS (Gibco) and the liquid collected and centrifuged at $7000 \mathrm{rpm}$ for $10 \mathrm{~min}$ at $4^{\circ} \mathrm{C}$. The concentration of ATP was determined in the supernatant with ATP determination kit (Invitrogen). For polymorphonuclear neutrophils detection,

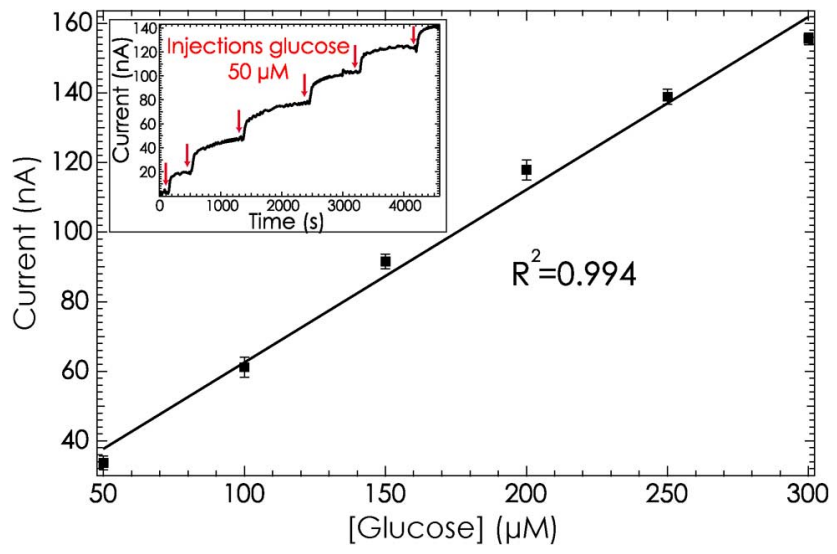

Fig. 8. Calibration line of glucose detection in CA (at a fix potential of $+650 \mathrm{mV}$ ) of the $1.2 \mathrm{~mm} \mathrm{WE}$ after electrodeposition of the chitosan/MWCNT dispersion and after functionalization with GOx. Error bars correspond to the standard deviation for 3 different measurements (confidence interval 95.4\%).

the pellet was resuspended in $0.2 \mathrm{~mL}$ RPMI $10 \%$ fetal bovine serum (Gibco) and analyzed at flow cytometer (FACS Canto, Becton Dickinson) with antibodies specific for CD11b and Gr1, labelled with allophycocyanin (APC) and fluorescein isothiocyanate (FITC, BioLegend), respectively.

\section{Characterization AND TESTS}

\section{A. Passive Chip Characterization}

1) Measurements of Glucose and Anti-Cancer Drugs: The characterization of the microfabricated sensor toward detection of glucose was performed with CA. After the electrodeposition of MWCNTs in chitosan and the functionalization of the $1.2 \mathrm{~mm}$ WE with the enzyme GOx, electrodes were tested for glucose sensitivity with CA at $+650 \mathrm{mV}$. The inset in Fig. 8 reports the current response of the $1.2 \mathrm{~mm}$ WE to repeated injections of glucose $50 \mu \mathrm{M}$. Well-defined current steps are visible every further injection of glucose. The calibration line reported in Fig. 8 is calculated from the evaluation of the current steps, by measuring the difference between the reached current value and the baseline (corresponding to the current at $0 \mu \mathrm{M}$ of glucose). We obtained a sensitivity of $63 \pm 15 \mu \mathrm{A} / \mathrm{mM} \cdot \mathrm{cm}^{2}$ and a LOD of $8 \pm 2 \mu \mathrm{M}$, which is relevant in many clinical applications [31], [32]. Many other metabolites of clinical interest (e.g., lactate, glutamate, ATP) can be monitored with our sensing platform, by changing the enzyme that is employed for the electrode functionalization.

The anti-cancer drugs ETO and MTX were monitored to test the performance of the sensing platform in $\mathrm{CV}$. CV has been found to be excellent for the determination of electroactive drugs in different biological fluids. Many drug compounds have been determined by voltammetric techniques, as for antibiotics, antiemetic, and others [33]. ETO is an anti-cancer drug, normally used in combination with other chemotherapeutic agents in the treatment of refractory testicular tumors and as first line treatment in patients with small cell lung cancer. It is known from literature that ETO is an electro-active compound and in $\mathrm{CV}$ it gives two well-defined oxidation peaks at around $+300 \mathrm{mV}$ and $+600 \mathrm{mV}$ (versus $\mathrm{Ag} \mid \mathrm{AgCl}$ ) [34]. Also MTX, an anti-neoplastic agent for the treatment of secondary progressive 


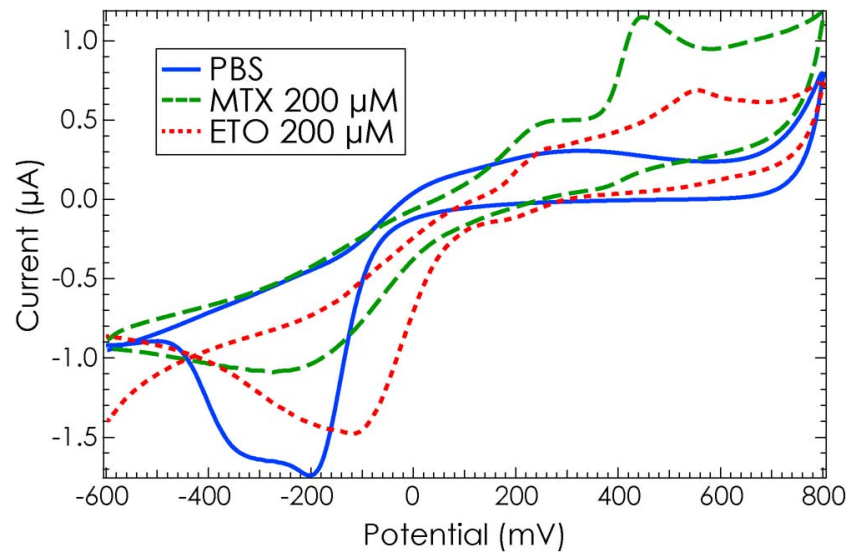

Fig. 9. Cyclic voltammograms of a bare electrode in PBS, in the presence of MTX $200 \mu \mathrm{M}$ and ETO $200 \mu \mathrm{M}$.

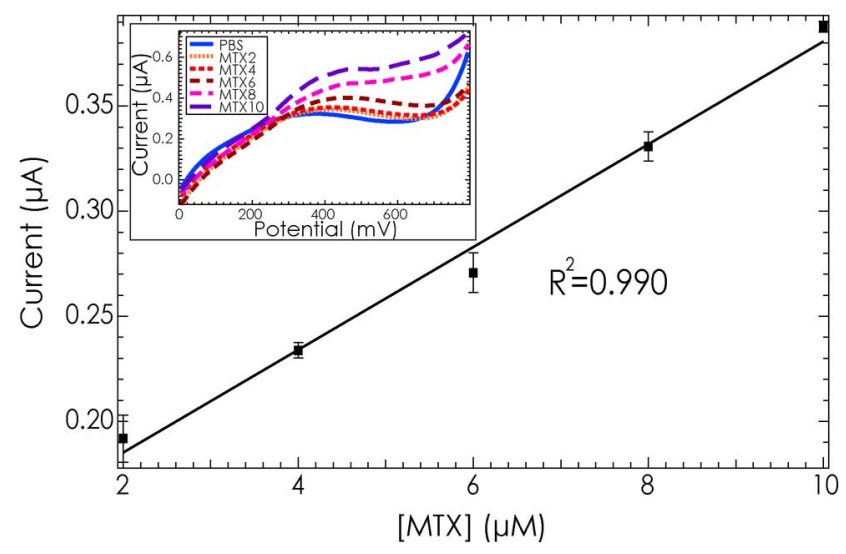

Fig. 10. Calibration curve for MTX within the physiological range in PBS, obtained in CV. Error bars correspond to the standard deviation for 4 different measurements (confidence interval 95.4\%). The inset shows the oxidation peak currents increasing with the drug concentration.

sclerosis, can be oxidized at a working electrode, through an irreversible electrode process that gives two oxidation peaks in $\mathrm{CV}$ : at $+500 \mathrm{mV}$ and $+700 \mathrm{mV}$ (versus $\mathrm{Ag} \mid \mathrm{AgCl}$ ) [35].

Fig. 9 shows the resulting cyclic voltammograms for a bare electrode (1.2 $\mathrm{mm}$ diameter) in PBS and in the presence of $200 \mu \mathrm{M}$ ETO and $200 \mu \mathrm{M}$ MTX. According to the literature, the voltammograms show two defined oxidation peaks for ETO (at $+300 \mathrm{mV}$ and $+600 \mathrm{mV}$ versus $\mathrm{Pt}$ ) and two oxidation peaks for MTX (at $+300 \mathrm{mV}$ and $+500 \mathrm{mV}$ vesus $\mathrm{Pt}$ ). With bare electrodes we also performed CV measurements to calibrate the sensors for MTX and ETO within the therapeutic range. Fig. 10 shows the dependence of the peak current on MTX concentrations. Similar curves were obtained also for ETO (data not showed). The y-axis values are the oxidation current peaks centered at $+500 \mathrm{mV}$. The inset in Fig. 10 shows the linear increase in current of the oxidation peaks at various MTX concentrations.

Table II summarizes the results in terms of sensitivity per unit area and limit of detection (LOD), obtained for the two drugs with a bare WE. For both drugs we obtained LODs that are compatible with the physiological ranges reported in the last column of Table II . These results prove that the sensing platform is capable to monitor drugs and metabolites within their therapeutic ranges.
TABLE II

SENSITIVITY, LOD AND THERAPEUTIC RANGES OF MTX AND ETO DeteCted IN CV With a Bare Electrode

\begin{tabular}{lccc}
\hline Drug & $\begin{array}{c}\text { Sensitivity } \\
\left(m A / m M * \mathrm{~cm}^{2}\right)\end{array}$ & $\begin{array}{c}\text { LOD } \\
(\mu M)\end{array}$ & $\begin{array}{c}\text { Therapeutic range } \\
(\mu M)\end{array}$ \\
\hline MTX & $2.3 \pm 0.7$ & $0.25 \pm 0.08$ & $1.8-3.3[36]$ \\
ETO & $0.15 \pm 0.04$ & $4.3 \pm 1.2$ & $33.9-101.9[37]$ \\
\hline
\end{tabular}

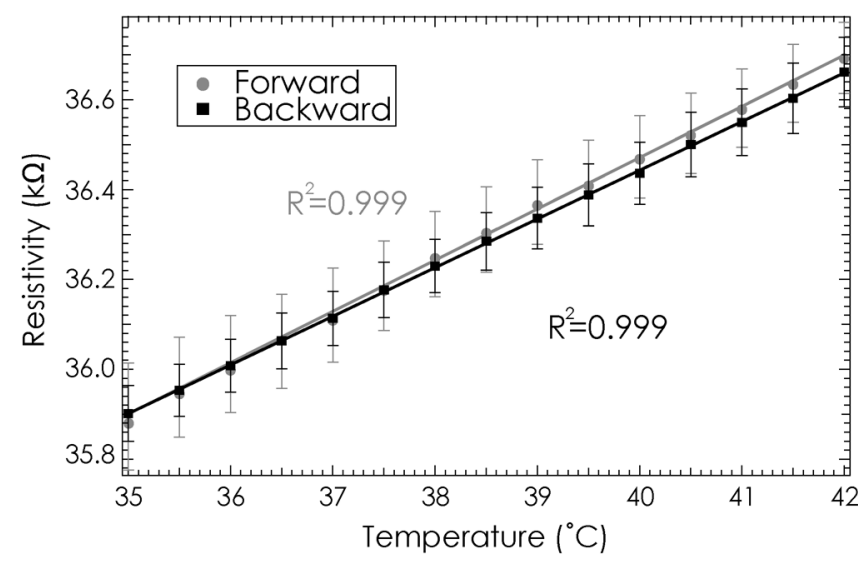

Fig. 11. Calibration curve for the temperature sensor (forward and backward scans), for a temperature range between $35^{\circ} \mathrm{C}$ and $42^{\circ} \mathrm{C}$.

2) Temperature Sensor: The resistive thermal device (RTD) consists of a Pt wire of $4 \mathrm{~nm}$ width and $93 \mathrm{~mm}$ length, with an average resistivity of $34 \mathrm{k} \Omega$ at $20^{\circ} \mathrm{C}$. Pt is commonly used in the production of resistive thermal devices and it was chosen because, among other metals employed in RTDs such as $\mathrm{Cu}$ and $\mathrm{Ni}, \mathrm{Pt}$ represents the best trade-off between linear behavior, biocompatibility, and higher metal resistivity, which allowed reducing the sensor sizes [38]. Fig. 11 shows the response of the Pt-RTD upon different temperatures in PBS. The temperature was first increased from $35^{\circ} \mathrm{C}$ to $42^{\circ} \mathrm{C}$ (forward scan) and then was inversely changed (backward scan). The Pt-RTD shows a linear behavior in the physiological temperature range with an average sensitivity of $0.11 \mathrm{k} \Omega /{ }^{\circ} \mathrm{C}$, which is comparable with the theoretical value of $0.13 \mathrm{k} \Omega /{ }^{\circ} \mathrm{C}$ (that can be calculated from the temperature coefficient of resistivity for $\mathrm{Pt}$, $\left.\alpha=0.00385^{\circ} \mathrm{C}^{-1}\right)$. High error bars are due to the low accuracy of the instrument used to measure the resistivity.

3) $p H$ Sensor: An external reference electrode double junction in $\mathrm{Ag} \mid \mathrm{AgCl}$ was used to obtain stable and reproducible measurements. IrOx is a well-known biocompatible material already used in the creation of implantable electrodes [29]. The $\mathrm{OCP}$ of an IrOx film changes in a predictable manner according to the solution $\mathrm{pH}$. Fig. 12 shows the calibration of the $\mathrm{pH}$ sensor in the squared version measured in the $\mathrm{pH}$ range from 5 to 9 . The $\mathrm{pH}$ of the buffer solution was continuously controlled with an external $\mathrm{pH}$ meter and we measured the corresponding OCP for the forward scan ( $\mathrm{pH}$ from 5 to 9) and for the backward scan (pH from 9 to 5). The inset of Fig. 12 shows the OCP measurements versus time. In the considered range, the potential changes linearly with increasing $\mathrm{pH}$, with a sensitivity of $-79.8 \pm 0.9 \mathrm{mV} / \mathrm{pH}$ for the forward scan, and $-79.1 \pm 1.2 \mathrm{mV} / \mathrm{pH}$ for the backward scan. These sensitivity values are quite close to the values reported in [29], and our 


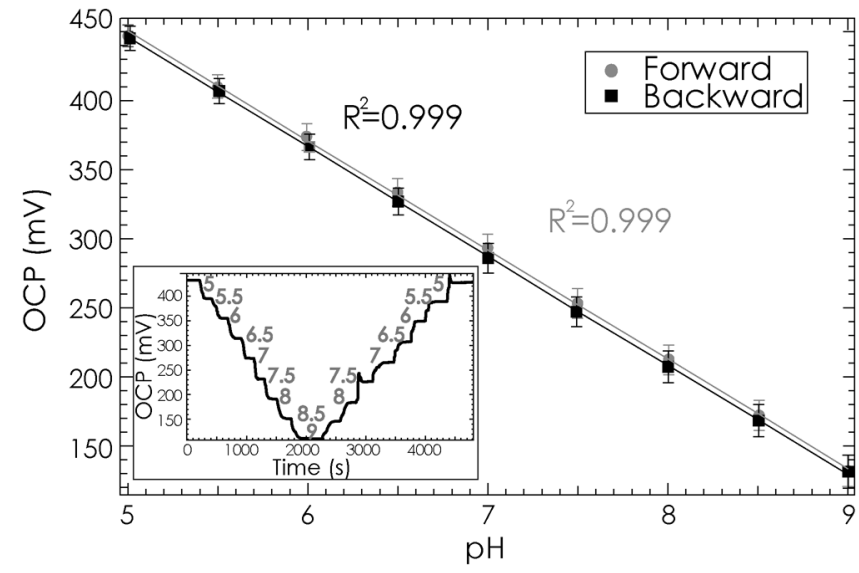

Fig. 12. Open circuit potential of the IrOx coated electrode to different $\mathrm{pH}$. The inset shows the OCP measurements versus time. The OCP steps correspond to different $\mathrm{pH}$ levels.

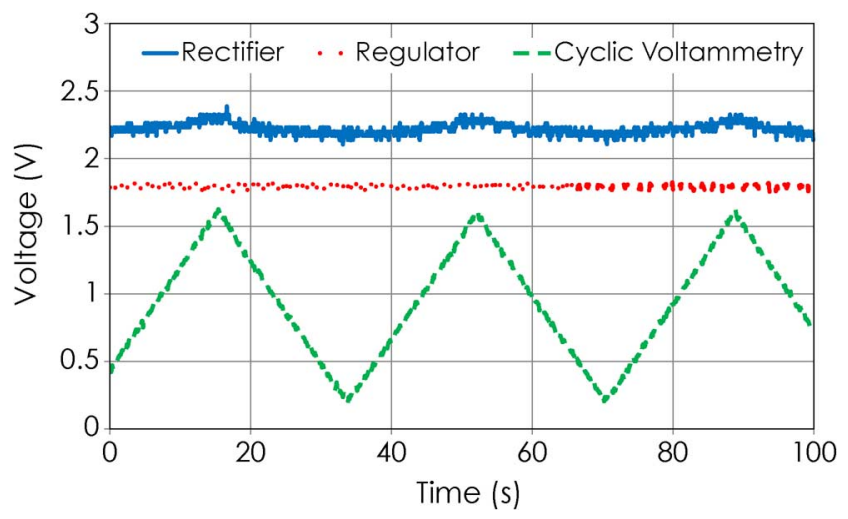

Fig. 13. The measured output waveform of the rectifier, regulator and the waveform generator for cyclic voltammetry when the inductive link is used for powering the system.

sensors shows good stability and reproducibility. The $\mathrm{pH}$ sensor showed in Fig. 6 is slightly different to the one used for these measurements (circular electrode with a diameter of $300 \mu \mathrm{m}$, instead of a squared $250 \times 250 \mu \mathrm{m}$ electrode), but we do not expect to obtain significantly different results.

\section{B. Active Chip Characterization}

We also performed some preliminary measurements by implementing together in an autonomous microsystem the main building blocks, which are: (i) the inductive coil; (ii) the power management IC; (iii) the interface IC to control and readout the biosensor; and (iv) the biosensor. This active autonomous system was tested in CV to measure the oxidation peaks of the anti-cancer drugs MTX and ETO. The measured voltage waveform at the output of the rectifier, regulator and the waveform generator are shown in Fig. 13 when the power management unit and the inductive link provides power to the waveform generator and readout circuits. The readout and waveform generator circuits were used for CV measurements on MTX and ETO. $\mathrm{CVs}$ were registered at room temperature under aerobic conditions by applying the triangular waveform with the slope of $82 \mathrm{mV} / \mathrm{sec}$ to the WE and a fixed voltage to the RE. The main oxidation peak position and its location (in voltage) for both
TABLE III

Comparison of the OXIDATION PEaK of ETO AND MTX MEASURED WITH THE COMMERCIAL EQUIPMENT AND THE ACTIVE CHIP

\begin{tabular}{cccccc}
\hline & \multicolumn{2}{c}{ Autolab } & & \multicolumn{2}{c}{ Active chip } \\
\cline { 2 - 3 } \cline { 5 - 6 } Drug & Voltage $(\mathrm{mV})$ & Current $(\mu \mathrm{A})$ & & Voltage $(\mathrm{mV})$ & Current $(\mu \mathrm{A})$ \\
\hline MTX & 535 & 0.81 & & 513 & 0.86 \\
ETO & 495 & 0.45 & & 495 & 0.43 \\
\hline
\end{tabular}

measurements are summarized in Table III. The measured oxidation current peak location and value has less than $7 \%$ discrepancy between our active chip and the Autolab potentiostat. More details on these measurements with the autonomous system can be found in [39].

\section{Biocompatible PACKAgING}

Potential sources of inflammation for implantable devices are attributed to the materials, shape and sizes of the devices [7]. MWCNTs were entrapped in a chitosan matrix to prevent toxicity due to the nano-particle nature of the MWCNTs and residues of the catalysts as well. To prevent leaking of potential hazardous substances and the corrosion of electronic components in contact with biologic fluids, a $10-\mu \mathrm{m}$ coating of Parylene C was employed [27]. For an implantable sensor, the development of a biocompatible packaging is essential for permitting wound healing, and ensuring prolonged sensor functionality. Most of biocompatible packaging from literature [40] require a mold (e.g., for packaging in PDMS) or the application of an additional membrane (e.g., polycarbonate membrane) that results in many manipulation steps that could affect the final biocompatibility grade. In this work, we assembled the passive sensing platform, with the blocks for power supply and the IC for the measurement, which were previously described (Section II), into an implantable compact device. Then, we developed a biocompatible packaging using an epoxy enhanced polyurethane membrane tested for the first time by Yu et al. [2]. Moreover the porosity of the membrane controls the passage of analytes to the electrodes, without the need of an additional membrane.

Fig. 14 shows photograph of the device after the mechanical milling, the deposition of Parylene $\mathrm{C}$, the electrode functionalization and the membrane dip-coating. This device was implanted in mice for 30 days to test the biocompatibility, which will be showed in the paragraph V.B, after the membrane in-vitro characterization, presented in the next paragraph.

\section{A. Membrane Characterization and Measurements}

In-vitro characterization of the membrane was performed on carbon-paste SPEs, in order to assess the optimized number of membrane layers and to understand the membrane effect on enzyme activity. After the functionalization with MWCNTs and GOx, electrodes were covered with 1-2-3 layers of the membrane, and finally tested for glucose sensitivity with CA at $+650 \mathrm{mV}$. Fig. 15 reports the effect of the curing temperature and membrane thickness on sensor sensitivity. The high temperature effect on biosensors without any membrane was investigated, showing a decrease in sensitivity probably due to a partial enzyme denaturation. However LOD was 


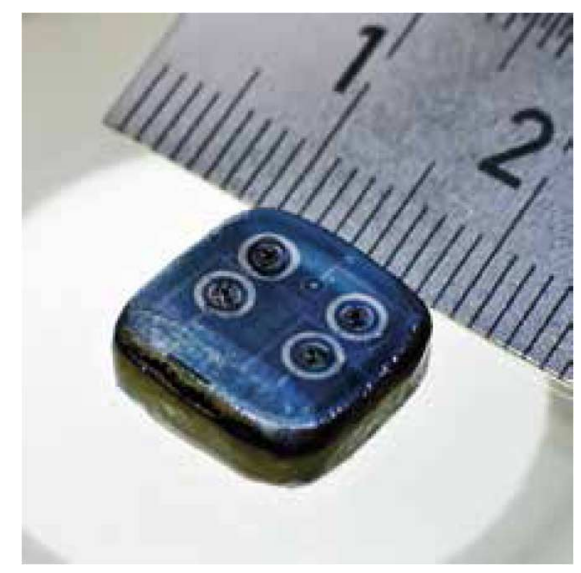

Fig. 14. Photograph of the final assembled device.

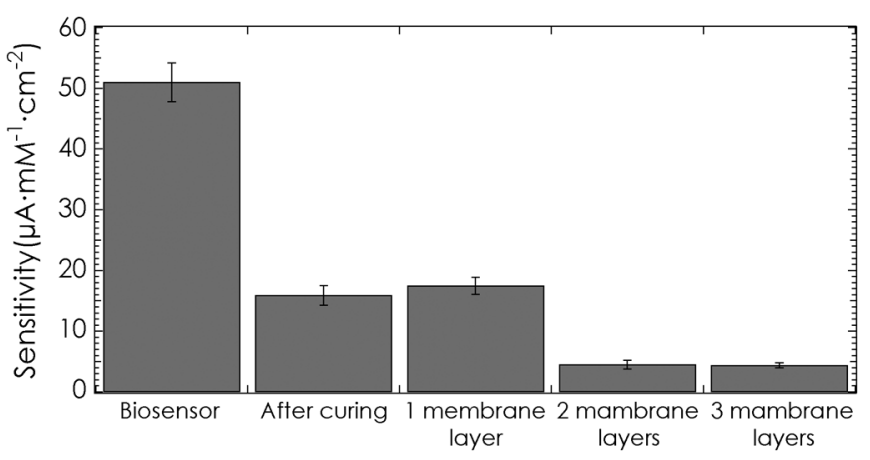

Fig. 15. Heat and membrane thickness effects on the sensor sensitivity (Error bars: standard error of three different SPE-based biosensors).

lower after the curing $(18 \pm 1 \mu \mathrm{M})$ compared to the case of a SPE-MWCNT/GOx biosensor $(73 \pm 8 \mu \mathrm{M})$, due to a reduction of the standard deviation of the background signal (data not shown). Last columns in Fig. 15 show that the application of one layer of membrane does not significantly change sensor performances, probably due to a not homogeneous coating. Two and three layers decrease the sensor sensitivity and increase the LOD $(90 \pm 23 \mu \mathrm{M}$ and $72.0 \pm 0.7 \mu \mathrm{M}$ respectively), but are the best trade-off between the decrease of sensitivity and a homogeneous cover. We also performed CA with our microfabricated passive chip. Working electrodes of $1.2 \mathrm{~mm}$ diameter, modified with MWCNTs in chitosan and GOx, were covered with 2-3 layers of the membrane. All the chips were tested for glucose sensitivity with $\mathrm{CA}$ at $+650 \mathrm{mV}$, and the sensitivity was then compared. Without any membrane we obtained a sensitivity of $63 \pm 15 \mu \mathrm{A} / \mathrm{mM} \cdot \mathrm{cm}^{2}$ and a LOD of $8 \pm 2 \mu \mathrm{M}$. With 2 layers of the membrane we obtained a lower sensitivity $\left(28 \pm 4 \mu \mathrm{A} / \mathrm{mM} \cdot \mathrm{cm}^{2}\right)$ but a lower LOD $(6 \pm 4 \mu \mathrm{M})$ due again to reduction of the standard deviation of the background signal. Similarly to SPE based sensor, the addition of a third membrane layer does not significantly affect the sensor performances: with 3 layers we obtained a sensitivity of $29 \pm 1 \mu \mathrm{A} / \mathrm{mM} \cdot \mathrm{cm}^{2}$ and a LOD of $7 \pm 4 \mu \mathrm{M}$. The long term stability of the coated biosensor was evaluated by CA for glucose sensitivity on SPEs for 40 days. The work in [41] reported a long term stability of 24 days using the same SPE

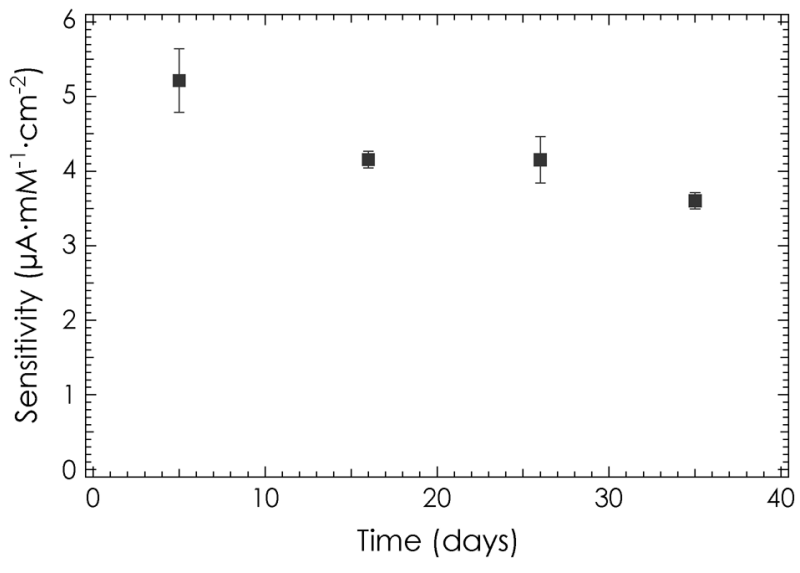

Fig. 16. Long term stability of a biosensor coated by 2 membrane layers (Error bars: standard error of two measurements on each day).

and GOx immobilized by adsorption onto MWCNT-working electrode. Fig. 16 shows that with two layers of epoxy enhanced polyurethane membrane the sensitivity slightly decreases with respect to time; the relative variation is equal to $28 \%$ after 35 days. The decrease of the sensor sensitivity is mainly due to the partial degradation of the enzyme activity over the time, and it represents the major challenge in the development of a long-term implantable sensor. However, as reported in [42], [43], it is possible to take into account the decrease in sensitivity with a one-point calibration method, thus increasing the sensor accuracy during long-time measurements.

\section{B. Biocompatibility In-Vivo Tests}

In order to investigate the in-vivo biocompatibility of the implantable sensor, we subcutaneously implanted four prototypes in mice for 30 days. At the end of the period, the implant site was washed with PBS, and levels of ATP and neutrophils in the elution liquid were quantified to follow the local inflammatory response. Changes in ATP concentration and changes in neutrophils percentage give information on the local cell death and on the status of tissue inflammation, respectively. Fig. 17 reports ATP and neutrophil variations in the liquid collected from the implant site. ATP and neutrophil levels were also evaluated for a commercial chip (DATA MARS), in case of induced inflammation (LPS) and for the negative control (mice with AP). In flow citometry, for the negative controls, the neutrophils level is barely detectable, while there is still a small amount of extracellular ATP due to mechanical stress created by fluid collection. Data from both neutrophil infiltration and ATP concentration suggest that the membrane provides a quite good biocompatible coverage. Furthermore, only in case of induced inflammation (LPS), local redness and swelling were visible. After 30 days, ATP and neutrophil levels are comparable with the negative control (AP), as well as for the commercial chip, and significantly lower than the positive control (LPS), proving that after 30 days the host seems to accept the implant. Unfortunately, a cell layer covered the surface of the sensing platform. Future steps will be the evaluation of the effect of this cell layer on sensing performances and the application of 


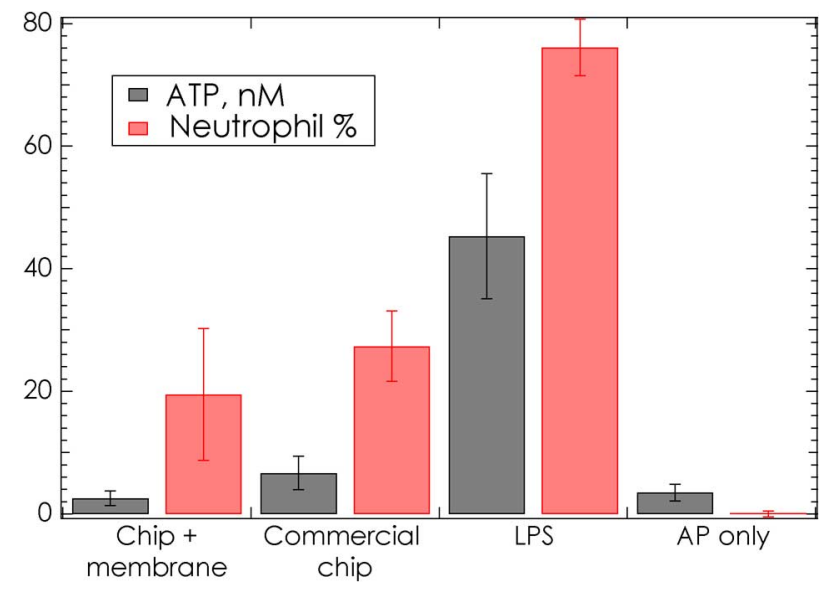

Fig. 17. ATP concentrations (nM) and percentages of neutrophils recovered from APs treated as indicated.

an anti-fouling agent on top of the membrane in order to reduce the cell adhesion.

\section{CONCLUSIONS}

In this work we showed the assembly into a fully-implantable device of a microfabricated sensing platform, power and data transmission and ICs. We show the design of each block of the device from a system level: readout circuits were designed to control and readout the biosensor array powered by the power management IC. The power is transferred to the battery-less implanted device though an optimized inductively coupled link over $30 \mathrm{~mm}$ distance. We finally describe the assembled integrated device intended to test the biocompatibility of the material used for the microfabrication. An epoxy enhanced polyurethane membrane was used to cover the device to ensure biocompatibility. An in-vitro characterization proved that the membrane is capable to retain enzyme activity up to 35 days. In-vivo experiment in mice proved that, after 30 days of implant, the membrane promotes the integration of the sensor with the surrounding tissue, as demonstrated by the low inflammation levels at the implant site. The system has been also tested for the measurement of the two anti-cancer drugs MTX and ETO, with CV method. The CV measurements which are reported in the Section IV-B showed that the redox peaks corresponding to the two compounds estimated in terms of maximum current and the voltage position are measured with less than $7 \%$ discrepancy, compared to the commercial equipment.

Future work will focus on the assembly of the ICs, the coil and the sensing platform in a fully-working prototype. Moreover, the problem of interfering compounds in biological fluids will be investigated through the employment of an additional membrane. The prototype will be employed for in-vivo measurements in mice inside the cage. In in-vivo testing we will also face other issues, such as the screening of interfering substances and the sensor selectivity.

\section{ACKNOWLEDGMENT}

A. Badertscher is acknowledged for the wire bonding and for his suggestions on the chip assembly.

\section{REFERENCES}

[1] F. Valgimigli, F. Lucarelli, C. Scuff, S. Morandi, and I. Sposato, "Evaluating the clinical accuracy of glucomen day: A novel microdialysis based continuous glucose monitor," J. Diabetes Sci. Technol., vol. 4, no. 5 , p. $1182,2010$.

[2] B. Yu, N. Long, Y. Moussy, and F. Moussy, “A long-term flexible minimally-invasive implantable glucose biosensor based on an epoxyenhanced polyurethane membrane," Biosens. Bioelectr., vol. 21, no. 12, pp. 2275-2282, 2006.

[3] D. A. Gough, L. S. Kumosa, T. L. Routh, J. T. Lin, and J. Y. Lucisano, "Function of an implanted tissue glucose sensor for more than 1 year in animals," Sci. Translation. Med., vol. 2, no. 42, pp. 42-53, 2010.

[4] S. Carrara, L. Bolomey, C. Boero, A. Cavallini, E. Meurville, G. De Micheli, T. R. Jost, M. Proietti, and F. Grassi, "Remote system for monitoring animal models with single-metabolite bio-nano-sensors," IEEE Sensors J., vol. 13, no. 3, pp. 1018-1024, 2013.

[5] P. D'Orazio, "Biosensors in clinical chemistry-2011 update," Clinica Chimica Acta, vol. 412, no. 19, pp. 1749-1761, 2011.

[6] S. Carrara, C. Baj-Rossi, C. Boero, and G. De Micheli, "Do carbon nanotubes contribute to electrochemical biosensing?," Electroch. Acta, 2014.

[7] S. Arens, U. Schlegel, G. Printzen, W. Ziegler, S. Perren, and M. Hansis, "Influence of materials for fixation implants on local infection an experimental study of steel versus titanium dcp in rabbits," J. Bone Joint Surg., vol. 78, pp. 647-651, 1996.

[8] E. G. Kilinc, M. A. Ghanad, F. Maloberti, and C. Dehollain, "Short range remote powering of implanted electronics for freely moving animals," in Proc. IEEE Int. New Circuits and Systems Conf., 2013, pp. $1-4$.

[9] N. Soltani, M. S. Aliroteh, and R. Genov, "Cellular inductive powering system for weakly-linked resonant rodent implants," in Proc. IEEE Biomedical Circuits and Systems Conf., 2013, pp. 350-353.

[10] M. H. Nazari, H. Mazhab-Jafari, L. Leng, A. Guenther, and R. Genov, "Cmos neurotransmitter microarray: 96-channel integrated potentiostat with on-die microsensors," IEEE Trans. Biomed. Circuits Syst., vol. 7, no. 3, pp. 338-348, 2013.

[11] M. R. Haider, S. K. Islam, S. Mostafa, M. Zhang, and T. Oh, "Lowpower low-voltage current readout circuit for inductively powered implant system," IEEE Trans. Biomed. Circuits Syst., vol. 4, no. 4, pp. 205-213, 2010.

[12] A. K. RamRakhyani, S. Mirabbasi, and M. Chiao, "Design and optimization of resonance-based efficient wireless power delivery systems for biomedical implants," IEEE Trans. Biomed. Circuits Syst., vol. 5 , no. 1, pp. 48-63, 2011.

[13] M. M. Ahmadi and G. A. Jullien, "A wireless-implantable microsystem for continuous blood glucose monitoring," IEEE Trans. Biomed. Circuits Syst., vol. 3, no. 3, pp. 169-180, 2009.

[14] C. Kotanen and A. Guiseppi-Elie, "Characterization of a wireless potentiostat for integration with a novel implantable biotransducer," IEEE Sensors J., vol. 14, no. 3, pp. 768-776, 2013.

[15] E. G. Kilinc and C. Dehollain, "Intelligent remote powering," PCT/ EP2013/056611, Aug. 13, 2013, Patent

[16] E. Kilinc, G. Conus, C. Weber, B. Kawkabani, F. Maloberti, and C. Dehollain, "A system for wireless power transfer of micro-systems in-vivo implantable in freely moving animals," IEEE Sensors J., vol. 14 , no. 2, pp. 522-531, 2014.

[17] E. G. Kilinc, C. Dehollain, and F. Maloberti, "Design and optimization of inductive power transmission for implantable sensor system," in Proc. Int. Workshop Symbolic and Numerical Methods, Modeling and Applications to Circuit Design, 2010, pp. 1-5.

[18] S. S. Ghoreishizadeh, S. Carrara, and G. De Micheli, "A configurable ic to contol, readout, calibrate an array of biosensors," in Proc. IEEE Eur. Conf. Circuit Theory and Design, 2013, pp. 1-4.

[19] S. S. Ghoreishizadeh, C. Baj-Rossi, A. Cavallini, S. Carrara, and G. De Micheli, "An integrated control and readout circuit for implantable multi-target electrochemical biosensing," IEEE Trans. Biomed. Circuits Syst.,, 2014, DOI: 10.1109/TBCAS.2014.2315157. 
[20] A. J. Bard and L. R. Faulkner, Electrochemical Methods: Fundamentals and Applications, 2nd ed. New York, NY, USA: Wiley, 1980, vol. 2.

[21] S. Ghoreishizadeh, C. Boero, A. Pullini, C. Baj-Rossi, G. De Micheli, and S. Carrara, "Sub-mw reconfigurable interface ic for electrochemical sensing," IEEE BioCAS, 2014, submitted for publication.

[22] J. Jung, S. Zhu, P. Liu, Y.-J. Chen, and D. Heo, "22-pj/bit energy-efficient 2.4-ghz implantable ook transmitter for wireless biotelemetry systems: In vitro experiments using rat skin-mimic," IEEE Trans. Microw. Theory Tech., vol. 58, no. 12, pp. 4102-4111, 2010.

[23] E. G. Kilinc, F. Maloberti, and C. Dehollain, "Remotely powered telemetry system with dynamic power-adaptation for freely moving animals," in Proc. IEEE BioCAS, Hsinchu, Taiwan, 2012, pp. 260-263.

[24] P. Cong, W. H. Ko, and D. J. Young, "Wireless batteryless implantable blood pressure monitoring microsystem for small laboratory animals," IEEE Sensors J., vol. 10, no. 2, pp. 243-254, 2010.

[25] I.-T. Hsieh, C. C.-H. Yang, C.-Y. Chen, G.-S. Lee, F.-J. Kao, K.-L. Kuo, and T. B.-J. Kuo, "Uninterrupted wireless long-term recording of sleep patterns and autonomic function in freely moving rats," $J$. Med. Biol. Eng., vol. 33, no. 1, pp. 79-86, 2013.

[26] S. Mirbozorgi, H. Bahrami, M. Sawan, and B. Gosselin, "A smart multicoil inductively-coupled array for wireless power transmission," IEEE Trans. Ind. Electron., vol. 61, pp. 6061-6070, 2014.

[27] A. Cavallini, C. Baj-Rossi, S. Ghoreishizadeh, G. De Micheli, and S Carrara, "Design, fabrication, test of a sensor array for perspective biosensing in chronic pathologies," in Proc. IEEE BioCAS, Hsinchu, Taiwan, 2012, pp. 124-127.

[28] C. Baj-Rossi, T. Rezzonico Jost, A. Cavallini, F. Grassi, G. De Micheli, and S. Carrara, "Continuous monitoring of naproxen by a cytochrome p450-based electrochemical sensor," Biosens. Bioelectr., vol. 53, no. 0, pp. 283-287, 32014.

[29] I. A. Ges, B. L. Ivanov, D. K. Schaffer, E. A. Lima, A. A. Werdich, and F. J. Baudenbacher, "Thin-film irox ph microelectrode for microfluidic-based microsystems," Biosens. Bioelectr., vol. 21, no. 2, pp. 248-256, 2005.

[30] J. Mocak, A. Bond, S. Mitchell, and G. Scollary, "A statistical overview of standard (iupac and acs) and new procedures for determining the limits of detection and quantification: Application to voltammetric and stripping techniques," Pure Appl. Chem., vol. 69, no. 2, pp. 297-328, 1997.

[31] P. E. Cryer, "Glucose counterregulation: Prevention and correction of hypoglycemia in humans," Amer. J. Phys.-Endocrin. Metab., vol. 264, no. 2, pp. E149-E155, 1993.

[32] V. H. Routh, "Glucose-sensing neurons: Are they physiologically relevant?," Physiol. Behav., vol. 76, no. 3, pp. 403-413, 2002.

[33] N. Abo El-Maali, "Voltammetric analysis of drugs," Bioelectrochem, vol. 64 , no. 1 , pp. 99-107, 2004.

[34] J. Holthuis, W. Van Oort, F. Römkens, J. Renema, and P. Zuman, "Electrochemistry of podophyllotoxin derivatives: Part i. Oxidation mechanism of etoposide (vp 16-213)," J. Electroanal. Chem. Interf. Electrochem., vol. 184, no. 2, pp. 317-329, 1985.

[35] A. Oliveira Brett, T. Macedo, D. Raimundo, M. Marques, and S. Serrano, "Electrochemical oxidation of mitoxantrone at a glassy carbon electrode," Anal. Chim. Acta, vol. 385, no. 1, pp. 401-408, 1999.

[36] K. N. Chi, M. E. Gleave, R. Klasa, N. Murray, C. Bryce, D. E. L. de Menezes, S. D'Aloisio, and A. W. Tolcher, "A phase i dose-finding study of combined treatment with an antisense bcl-2 oligonucleotide (genasense) and mitoxantrone in patients with metastatic hormone-refractory prostate cancer," Clin. Canc. Res., vol. 7, no. 12, pp. $3920-3927,2001$

[37] J. J. Holthuis, P. E. Postmus, W. J. Van Oort, B. Hulshoff, H. Verleun, D. T. Sleijfer, and N. H. Mulder, "Pharmacokinetics of high dose etoposide (vp 16-213)," Eur. J. Canc. Clin. Onc., vol. 22, no. 10, pp. $1149-1155,1986$.

[38] B. Baker, "Temperature sensing technologies," AN679, Microchip Technology Inc., 1998.

[39] S. Ghoreishizadeh, E. G. Kilinc, C. Baj-Rossi, G. De Micheli, C. Dehollain, and S. Carrara, "An implantable bio-micro-system for drug monitoring," in Proc. IEEE BioCAS, Rotterdam, Netherlands, 2013.

[40] S. Vaddiraju, I. Tomazos, D. J. Burgess, F. C. Jain, and F. Papadimitrakopoulos, "Emerging synergy between nanotechnology and implantable biosensors: A review," Biosens. Bioelectr., vol. 25, no. 7, pp. $1553-1565,2010$

[41] C. Boero, S. Carrara, and G. De Micheli, "Long-term biosensors for metabolite monitoring by using carbon nanotubes," Sens. Transduc. J., vol. 125 , no. 2, pp. 229-237, 2011.
[42] C. Choleau, J. Klein, G. Reach, B. Aussedat, V. Demaria-Pesce, G. Wilson, R. Gifford, and W. Ward, "Calibration of a subcutaneous amperometric glucose sensor implanted for 7 days in diabetic patients: Part 2. Superiority of the one-point calibration method," Biosens. Bioelectr., vol. 17, no. 8, pp. 647-654, 2002.

[43] S. P. Nichols, A. Koh, W. L. Storm, J. H. Shin, and M. H. Schoenfisch, "Biocompatible materials for continuous glucose monitoring devices," Chem. Rev., vol. 113, no. 4, pp. 2528-2549, 2013.

Camilla Baj-Rossi received the M.Sc. degree in biomedical engineering from Politecnico di Torino, Torino, Italy, in 2010.

Currently, she is working toward the Ph.D. degree in the Laboratory of Integrated Systems at École Polytechnique Fédérale de Lausanne (EPFL), Lausanne, Switzerland. Her research interests include the development of a point-of-care biosensor array based on multiwalled carbon-nanotubes and enzymes to detect drugs and metabolites in biological fluids.

Enver G. Kilinc received the B.Sc. degree in electronic engineering from Istanbul Technical University (ITU), Istanbul, Turkey, in 2008, and the M.Sc. degree in electrical and electronic engineering and the Ph.D. degree in wireless power transmission and radio frequency identification from École Polytechnique Fédérale de Lausanne (EPFL), Lausanne, Switzerland, in 2010 and 2014, respectively.

In March 2010, he joined the Electronics Laboratory at EPFL as a Research Assistant in the field of RFIC design. His research interests include remote powering and wireless telemetry for wireless sensor networks and biomedical applications, analog circuit design, and RF integrated circuits.

Sara S. Ghoreishizadeh received the B.Sc degree in electrical engineering and the M.Sc. degree in microelectronics circuits from the Sharif University of Technology, Tehran, Iran, in 2007 and 2009, respectively.

Currently, she is a Research Assistant and working toward the Ph.D. degree in the Integrated Systems Laboratory at École Polytechnique Fédérale de Lausanne, Lausanne, Switzerland. Her research is focused on design and implementation of low power analog/mixed-signal IC to readout, control, and calibrate multi-target electrochemical biosensors. Her interests include designing dedicated circuits for health care monitoring and personalized therapy within highly-integrated implantable devices.

Daniele Casarino received the M.Sc. degree, following an internship at the Integrated Systems Laboratory, from École Polytechnique Fédérale de Lausanne (EPFL), Lausanne, Switzerland, in 2013.

$\mathrm{He}$ is a Biomedical Engineer at Universitá degli Studi di Genova, Genova, Italy. At EPFL, he investigated polymeric packaging for fully implantable biosensors. Since February 2014, he has worked as a Service Engineer at Carestream Health, Genova, Italy.

Tanja Rezzonico Jost received the M.Sc. degree with honors in veterinarian biotechnology from the University of Milan, Milan, Italy.

Currently, she is responsible for in-vivo experiments at the T Cell Development Laboratory, Institute for Research in Biomedicine, Bellinzona, Switzerland. Her current research interests include modeling human pathological conditions and identifying biomarkers in chronic inflammatory diseases.

Catherine Dehollain received the M.Sc. degree in electrical engineering and the Ph.D. degree from École Polytechnique Fédérale de Lausanne (EPFL), Lausanne, Switzerland, in 1982 and 1995, respectively.

From 1982 to 1984, she was a Research Assistant at the Electronics Laboratories (LEG) at EPFL. In 1984, she joined the Motorola European Center for Research and Development, Geneva, Switzerland, where she designed integrated circuits applied to telecommunications. In 1990, she joined EPFL as a Senior Assistant at the "Chaire des Circuits et Systmes," where she was involved in impedance broadband matching. Since 1995, she has been responsible for the RFIC Group, EPFL, for RF activities. She has been the Technical Project Manager of the European projects, CTI projects, and the Swiss National Science 
Foundation projects dedicated to RF wireless micropower sensor networks and mobile phones. Since 1998, she has been a Lecturer at EPFL in the area of RF circuits, electric filters, and CAD tools. Since 2006, she has been a "Maítre d'Enseignement et de Recherche" at EPFL. She is an author or coauthor of four scientific books and 120 scientific publications. Her current research interests include low power analog circuits, biomedical remotely powered sensors, and electric filters.

Fabio Grassi received the M.Sc. degree in medicine from the University of Pavia, Pavia, Italy, and the Ph.D. degree in microbiology from the University of Milan, Milan, Italy, in 1985 and 1993, respectively.

He was an Anna Villa Rusconi Fellow with the University of Umeä, Umeä, Sweden, in 1988, a Postdoctoral Fellow with the Institut Pasteur, Paris, France, from 1989 to 1993, an Assistant Professor with the San Raffaele Scientific Institute, Milan, Italy, from 1994 to 1998, a Marie Curie Fellow with Hôpital Necker, Paris, from 1998 to 2000, and a Special Fellow of the Leukemia and Lymphoma Society with the Dana Farber Cancer Institute, Harvard Medical School, Boston, MA, USA, from 2000 to 2002. Currently, he is an Associate Professor of Cell Biology in the Medical School at the University of Milan. In 2002, he joined the Institute for Research at Biomedicine Bellinzona, Bellinzona, Switzerland, as the Head of the T Cell Development Laboratory. His research interests include T cell physiology, signal transduction, control of cell growth and intercellular communications during $\mathrm{T}$ cell development, and immunopathological conditions.

Laura Pastorino received the M.Sc. degree in chemical engineering and the Ph.D. degree in biophysics from the University of Genova, Genova, Italy, in 1999 and 2003, respectively.

Currently, she is an Assistant Professor of Bioengineering in the Department of Informatics, Bioengineering, Robotics and Systems Engineering at the University of Genova. Her research interests include nanobiotechnology for drug delivery and tissue engineering.

Giovanni De Micheli received the nuclear engineer degree from Politecnico di Milano, Italy, in 1979, and the M.S. and Ph.D. degrees in electrical engineering and computer science from the University of California, Berkeley, CA, USA, in 1980 and 1983 , respectively.
Currently, he is a Professor and Director of the Institute of Electrical Engineering and of the Integrated Systems Center at École Polytechnique Fédérale de Lausanne (EPFL), Lausanne, Switzerland. He is Program Leader of the NanoTera.ch program. Previously, he was Professor of Electrical Engineering at Stanford University, Stanford, CA, USA. His research interests include several aspects of design technologies for integrated circuits and systems, such as synthesis for emerging technologies, networks on chips and 3D integration. $\mathrm{He}$ is also interested in heterogeneous platform design including electrical components and biosensors, as well as in data processing of biomedical information. He authored Synthesis and Optimization of Digital Circuits (New York, NY, USA: McGraw-Hill, 1994) and has coauthored and/or coedited eight other books and more than 500 technical articles.

Dr. DeMicheli is a Fellow of ACM and a member of the Academia Europaea and the Scientific Advisory Board of IMEC and STMicroelectronics. He was the recipient of the 2012 IEEE/CAS Mac Van Valkenburg Award for contributions to theory, practice, and experimentation in design methods and tools and of the 2003 IEEE Emanuel Piore Award for contributions to computer-aided synthesis of digital systems. He received the Golden Jubilee Medal for outstanding contributions to the IEEE CAS Society in 2000, the D. Pederson Award for the best paper in the IEEE TRANSACTIONS ON COMPUTER-AIDED DESIGN OF INTEGRATED CIRCUITS AND SYSTEMS in 1987, and several Best Paper Awards, including DAC (1983 and 1993), DATE (2005) and Nanoarch (2010 and 2012).

Sandro Carrara received the M.Sc. degree from the University of Genova, Genova, Italy, and the Ph.D. degree in biochemistry and biophysics from the University of Padua, Padova, Italy, in 1993 and 1997, respectively.

He is a Lecturer at École Polytechnique Fédérale de Lausanne (EPFL), Lausanne, Switzerland. He is a former Professor of optical and electrical biosensors in the Department of Electrical Engineering and Biophysics (DIBE), University of Genova, and a former Professor of nanobiotechnology at the University of Bologna, Italy. His scientific interests are on electrical phenomena of nano-biostructured films, and include CMOS design of biochips based on proteins and DNA. He has authored more than 170 scientific publications and 12 patents. He has had several Top 25 Hottest Articles (2004, 2005, 2008, 2009, and twice in 2012) published in highly-ranked international journals.

Dr. Carrara is founder and Editor-in-Chief of the journal BioNanoScience, Topical Editor of the IEEE SENSORS JOURNAL, and Associate Editor of the IEEE TRANSACTIONS ON BIOMEDICAL CIRCUITS AND SYSTEMS. He is a member for the IEEE Circuits and Systems Society (CASS) and member of the Board of Governors of the IEEE Sensors Council. He has been appointed as CASS Distinguished Lecturer for 2013 and 2014. 